\title{
Cold-pressed oil from Citrus aurantifolia inhibits the proliferation of vascular smooth muscle cells via regulation of PI3K/MAPK signaling pathways
}

\author{
BYEONG-WOOK SONG ${ }^{1}$, CHANG YOUN LEE $^{2}$, JUN-HEE PARK ${ }^{3}$, BOMI KIM $^{4}$, SEAHYOUNG LEE $^{1}$, \\ SOYEON LIM ${ }^{1}$, SANG WOO KIM ${ }^{1}$, JUNG-WON CHOI ${ }^{1}$, MISUN KANG ${ }^{1}$, JUNG HWA KANG ${ }^{5}$, \\ SUNG-SUK LEE $^{6}$, MI-JIN PARK ${ }^{6}$, HANBYEOL MOON $^{7}$, KI-CHUL HWANG $^{1}$ and IL-KWON KIM ${ }^{1,8}$ \\ ${ }^{1}$ Institute for Bio-Medical Convergence, College of Medicine, Catholic Kwandong University, \\ Gangneung, Gangwon 25601; ${ }^{2}$ Pharmacology and Drug Abuse Research Group, Research Center of \\ Convergence Toxicology, Korea Institute of Toxicology, Daejeon 34114; ${ }^{3}$ Medical Science Research Institute; \\ ${ }^{4}$ Institute for Bio-Medical Convergence, Catholic Kwandong University International St. Mary's Hospital; \\ ${ }^{5}$ IMMUNISBIO Co., Ltd., International St. Mary's Hospital, Incheon 22711; ${ }^{6}$ Division of Wood Chemistry and \\ Microbiology, Department of Forest Products, National Institute of Forest Science, Seoul 02455; ${ }^{7}$ Department of \\ Integrated Omics for Biomedical Sciences, Graduate School, Yonsei University, Seoul 03722; ${ }^{8}$ Cell Therapy Center, \\ Catholic Kwandong University International St. Mary's Hospital, Incheon 22711, Republic of Korea
}

Received December 17, 2020; Accepted August 31, 2021

DOI: $10.3892 / \mathrm{etm} .2021 .10943$

\begin{abstract}
Vascular occlusive disease is a chronic disease with significant morbidity and mortality. Although a variety of therapies and medications have been developed, the likelihood of disease re-emergence is high and this can be life-threatening. Based on a previous screening experiment related to vascular obstructive diseases using 34 types of essential oils, cold-pressed oil (CpO) from Citrus aurantifolia (lime) has been demonstrated to have the best effect for the inhibition of vascular smooth muscle cells (VSMCs) proliferation. The aim of the present study was to evaluate the effect of lime $\mathrm{CpO}$ on the pathological changes of VSMCs. To determine this, the effect of lime $\mathrm{CpO}$ on VSMC proliferation, a major cause of vascular disease, was investigated. To determine the safe concentration interval for toxicity of $\mathrm{CpO}$ during VSMC culture, a dilution of $1 \times 10^{-5}$ was determined using Cell Counting Kit-8 assay, which was confirmed to be non-toxic using a lactate dehydrogenase assay. To examine the effect of lime $\mathrm{CpO}$ in cellular signaling pathways, changes in phosphorylation of both the PI3K/AKT/mTOR and extracellular signal-regulated MEK/ERK signaling pathways with serum were investigated. Furthermore, lime $\mathrm{CpO}$ with $\mathrm{FBS}$ also
\end{abstract}

Correspondence to: Dr Il-Kwon Kim, Cell Therapy Center, Catholic Kwandong University International St. Mary's Hospital, 25 Simgok-ro 100 Beon-gil, Seo, Incheon 22711, Republic of Korea E-mail: ilkwonkim@cku.ac.kr

Key words: cell cycle, Citrus aurantifolia, cold-pressed oil, proliferation, vascular smooth muscle cells significantly decreased the expression levels of the cell cycle regulators cyclin D1 and proliferating cell nuclear antigen. Additionally, lime $\mathrm{CpO}$ with FBS significantly inhibited the sprouting of VSMCs in an ex vivo culture system. These results suggested that lime $\mathrm{CpO}$ inhibited the abnormal proliferation of VSMCs and can be developed as a nature-based therapeutic agent for obstructive vascular disease.

\section{Introduction}

Vascular smooth muscle cells (VSMCs) and endothelial cells (ECs) are the main cell types that constitute the blood vessels, with their function being to control blood vessel pressure and tension (1). VSMCs maintain homeostasis in a contractile form with little proliferation under physiological conditions $(2,3)$. However, when ECs are damaged, inflammatory factors secreted in response to pathological conditions cause abnormal proliferation of VSMCs, initiating their transformation to the synthetic phenotype due to internal and external changes (3-5). This abnormal proliferation of VSMCs is known to cause arteriosclerosis and restenosis $(6,7)$. Classical surgical therapies for treating these vascular diseases, such as coronary artery bypass grafting or stent-grafted angioplasty, are effective for a short period of time. However, these surgical treatments can cause blood flow disorders due to the abnormal proliferation of VSMCs over time (8). To overcome this problem, a drug-coated stent has been developed to treat vascular diseases more effectively (9). However, the potential for restenosis due to VSMC proliferation remains a major long-term threat (8). Therefore, the development of novel therapeutic agents for the treatment of vascular diseases is still required.

It has been reported that natural compounds have a positive effect on cardiovascular diseases and improve some vascular 
functions (9). One of the promising novel treatments of vascular diseases in various natural products is essential oils (EOs). EOs and their constituents are promising as therapeutic agents as they have been demonstrated to functionally improve cardiovascular disease $(10,11)$.

Lime (Citrus aurantifolia) is widely cultivated worldwide and is an excellent source of vitamins, particularly vitamin $C$. Lime EO has previously been used as a fragrance, an antimicrobial agent and for aromatherapy $(12,13)$. Lime EO contains limonene, $\beta$-pinene, $\gamma$-terpinene, citral and linarul, among other compounds. Lime EO is a volatile complex mixture and has been used as a means to prevent, improve and treat diseases (14). Furthermore, the potential for the use of lime EO as chemotherapy in the prevention and treatment of inflammatory diseases $(15,16)$, cancer $(17,18)$ and oxidative stress $(19,20)$, has been reported in various studies. Regarding the applications in cardiovascular disease, it has been demonstrated that daily intake of lemon (Citrus limon), a Citrus species that has a similar nutritional value to lime, lowers systolic blood pressure (21).

To the best of our knowledge, the effect of cold-pressed oil (CpO) from limes on VSMC pathological changes is unclear. It was hypothesized that lime $\mathrm{CpO}$ could inhibit the proliferation of VSMC through known vascular signaling pathways $(22,23)$ in cardiovascular disease. The present study investigated whether lime $\mathrm{CpO}$ could modulate the MAPK and PI3K signaling pathways to reduce abnormal cell proliferation induced by FBS.

\section{Materials and methods}

Lime $\mathrm{CpO}$. Cold pressed lime oil was purchased from Sydney Essential Oil Company. Coupled gas chromatography-mass spectrometry (GC-MS) analysis was performed using a Thermo Scientific Model ISQ LT (Thermo Fisher Scientific, Inc.) equipped with both a flame ionization detector (FID) and a mass spectrometer.

GC-MS analysis. A Durabond-5MS capillary column (60 m x $0.25 \mathrm{~mm} \times 0.25 \mu \mathrm{m}$ film thickness; Agilent Technologies, Inc.) was used. The carrier gas, helium, had a constant flow rate of $1 \mathrm{ml} / \mathrm{min}$. The injection temperature was $250^{\circ} \mathrm{C}$ and $1 \mu \mathrm{l}$ of the sample was injected with a split ratio of 1:20. The oven temperature was maintained at $50^{\circ} \mathrm{C}$ for $5 \mathrm{~min}$, then increased by $10^{\circ} \mathrm{C} / \mathrm{min}$ to $65^{\circ} \mathrm{C}$ and held for $30 \mathrm{~min}$, increased by $5^{\circ} \mathrm{C} / \mathrm{min}$ to $120^{\circ} \mathrm{C}$ and held for $15 \mathrm{~min}$, increased by $1^{\circ} \mathrm{C} / \mathrm{min}$ to $140^{\circ} \mathrm{C}$ and held for $11 \mathrm{~min}$, increased by $10^{\circ} \mathrm{C} / \mathrm{min}$ to $250^{\circ} \mathrm{C}$ and held for $5 \mathrm{~min}$, and finally increased by $20^{\circ} \mathrm{C} / \mathrm{min}$ to $325^{\circ} \mathrm{C}$ and held for $6 \mathrm{~min}$. For the FID, the temperature was set to $300^{\circ} \mathrm{C}$, air flow was set to 350 $\mathrm{ml} / \mathrm{min}$, hydrogen flow was set to $35 \mathrm{ml} / \mathrm{min}$ and the make-up gas (helium) flow was set to $40 \mathrm{ml} / \mathrm{min}$. The mass interface temperature was $250^{\circ} \mathrm{C}$ and the ion source temperature was $250^{\circ} \mathrm{C}$. Mass scan data were acquired in electron ionization (EI) mode at a $0.2 \mathrm{sec}$ scan time rate with a scan range of 35-550 amu. The identification of peaks was performed by comparing the peak average mass spectrum of the peak with an electronic library database (National Institute of Standards and Technology, Environmental Protection Agency and National Institutes of Health Mass Spectral Library; version $2.0 \mathrm{~g}$ : https://chemdata.nist.gov/). The identity of the compounds was assigned by comparison of the Kovats retention index, determined in relation to a homologous series of n-alkanes (C7-C30).

Animal care. All animal experiments were approved by the Institutional Animal Care and Use Committee of Catholic Kwandong University, International St. Mary's Hospital (Incheon, South Korea; approval no. CKU 01-2019-008) in cooperation with the Association for Assessment and Accreditation of Laboratory Animal Care and performed in accordance with the Guidelines and Regulations for Animal Care (24). Rats were housed in a room with a stable temperature of $22.5 \pm 1.5^{\circ} \mathrm{C}, 50-60 \%$ humidity and $12 \mathrm{~h}$ light-dark cycles with ad libitum access to food and water. A total of 16 rats were divided into four groups: control (non-treated), lime CpO, FBS (FBS only treated), and FBS and lime CpO. Rats were intramuscularly anesthetized with Zoletil ${ }^{\mathrm{TM}} 50$ (tiletamine:zolazepam = 1:1; $20 \mathrm{mg} / \mathrm{kg}$; Virbac) and Rompun $2 \%$ (xylazine; $5 \mathrm{mg} / \mathrm{kg}$; Bayer AG), and euthanized via an intraperitoneal overdose of sodium pentobarbital (100-200 mg/kg). Euthanasia was confirmed with lack of heartbeat.

Isolation and culture of rat aortic VSMCs. Rat aortic VSMCs were isolated as previously described $(25,26)$. Thoracic aortas from male Sprague-Dawley rats (Orient Bio; $n=3$; weight, 200-250 g; age, 6-8 weeks) were removed and transferred to incubate in serum-free DMEM (Invitrogen; Thermo Fisher Scientific, Inc.) containing $100 \mathrm{U} / \mathrm{ml}$ penicillin and $100 \mu \mathrm{g} / \mathrm{ml}$ streptomycin. The aortas were separated from the connective tissue and transferred to a petri dish containing $5 \mathrm{ml}$ of an enzyme dissociation mixture, composed of DMEM with $1 \mathrm{mg} / \mathrm{ml}$ collagenase type I (Sigma-Aldrich; Merck KGaA) and $0.5 \mu \mathrm{g} / \mathrm{ml}$ elastase (Thermo Fisher Scientific, Inc.), and incubated for $30 \mathrm{~min}$ at $37^{\circ} \mathrm{C}$. The aortas were then transferred to DMEM and the adventitia was stripped off each aorta with forceps under an optical microscope. Subsequently, the aortas were transferred to a conical tube containing $5 \mathrm{ml}$ of enzyme dissociation mixture containing DMEM with $1 \mathrm{mg} / \mathrm{ml}$ of collagenase type I (Sigma-Aldrich; Merck KGaA) and $0.5 \mu \mathrm{g} / \mathrm{ml}$ of elastase (Thermo Fisher Scientific, Inc.) and incubated for $2 \mathrm{~h}$ at $37^{\circ} \mathrm{C}$. The suspension was centrifuged at $320 \mathrm{x}$ g for $10 \mathrm{~min}$ at room temperature and the pellet was re-suspended in DMEM with $10 \%$ FBS (Atlas Biologicals, Inc) under room temperature. Rat aortic VSMCs were cultured in DMEM supplemented with $10 \% \mathrm{FBS}, 1 \%$ penicillin-streptomycin in $75-\mathrm{cm}^{2}$ flasks in a $37^{\circ} \mathrm{C}$ incubator with $5 \% \mathrm{CO}_{2}$ (Thermo Fisher Scientific, Inc.). Isolated cells from 3 different animals in passages 5-8 were used in the present study.

CpO treatment. The concentration of $\mathrm{CpO}$ on VSMCs culture was determined as 10-5 dilution after Cell Counting Kit-8 (CCK-8) assay. For treatment with CpO, VSMCs were seeded into 96 -well plates at a density of $5 \times 10^{3}$ cells/well. VSMCs were serum-starved in DMEM containing 0.5\% FBS for $24 \mathrm{~h}$ and treated with or without 5\% FBS in DMEM for the following $24 \mathrm{~h}$ to detect the effects of lime $\mathrm{CpO}$ under in vitro and ex vivo conditions in a $37^{\circ} \mathrm{C}$ incubator. In order to check the cell signal transduction, MEK1/2 inhibitor U0126 (10 $\mu \mathrm{M}$; Cell Signaling Technology, Inc.) and mTOR inhibitor 
Rapamycin (20 nM; Calbiochem; Merck KGaA) were treated with $5 \%$ FBS for $24 \mathrm{~h}$.

Cell proliferation assay. A CCK-8 (DoGenBio Co., Ltd.) assay was used according to the manufacturer's protocol. To each well, $10 \%$ (v/v) CCK-8 reagent was added and incubated at $37^{\circ} \mathrm{C}$ for $2 \mathrm{~h}$ to allow for the formation of water-soluble tetrazolium salts (WST)- 8 formazan. The absorbance at $450 \mathrm{~nm}$ was measured using a microplate reader (Thermo Fisher Scientific, Inc.).

Cytotoxicity assay. The Cytotoxicity Lactate Dehydrogenase (LDH) Assay Kit-WST (cat. no. MK401; Takara Bio, Inc.) was used according to the manufacturer's protocol. Cell suspension and $50 \mu \mathrm{l}$ DMEM were sequentially added into a 96-well culture plate $\left(7 \times 10^{3}\right.$ cells/well) and samples were incubated at $37^{\circ} \mathrm{C}$ for $24 \mathrm{~h}$. Samples were mixed with $100 \mu$ l working solution at room temperature for $30 \mathrm{~min}$ in the dark. The absorbance at $490 \mathrm{~nm}$ was measured using a microplate reader (Thermo Fisher Scientific, Inc.).

Western blotting. VSMCs were washed once with PBS and lysed using RIPA lysis buffer (Thermo Fisher Scientific, Inc.). Total protein concentration was quantified using an albumin standard (bioPLUS ${ }^{\mathrm{TM}}$; BioWORLD). Proteins were then separated by $10 \%$ SDS-PAGE by $15-20 \mathrm{mg} / \mathrm{ml}$ of protein loading per lane and transferred to a PVDF membrane (MilliporeSigma). After blocking of the membrane with TBS with $0.1 \%$ Tween-20 (TBS-T; BioPLUS Chemicals) and $5 \%$ (w/v) BSA (bioPLUS ${ }^{\mathrm{TM}}$; BioWORLD) in 0.1\% TBS-T for $1 \mathrm{~h}$ at room temperature, the membrane was washed twice with TBS-T and incubated with the primary antibodies diluted in blocking buffer a ratio of 1:1,000 to 1:2,000 overnight at $4^{\circ} \mathrm{C}$. The membrane was washed three times with TBS-T for $5 \mathrm{~min} /$ wash and incubated for $1 \mathrm{~h}$ at room temperature with horseradish peroxidase-conjugated secondary antibodies diluted in blocking buffer a ratio of 1:4,000. The membrane was subsequently washed six times with TBS-T for $5 \mathrm{~min} /$ wash and bands were detected with an enhanced chemiluminescence reagent (Abclon, Inc.). Band intensities were semi-quantified using a Davinch-Western Imaging System (Davinch-K Co., Ltd.) and ImageJ version 1.44p software (National Institutes of Health). The following antibodies were used in these experiments: anti-PI3K (cat. no. sc-7189; Santa Cruz Biotechnology, Inc.), anti-phosphorylated (p)-PI3K (cat. no. 4228S; Cell Signaling Technology, Inc.), anti-AKT (cat. no. 9272S; Cell Signaling Technology, Inc.), anti-p-AKT (cat. no. 9271S; Cell Signaling Technology, Inc.), anti-mTOR (cat. no. 2972S; Cell Signaling Technology, Inc.), anti-p-mTOR (cat. no. 2971S; Cell Signaling Technology, Inc.), anti-MEK (cat. no. 9122; Cell Signaling Technology, Inc.), anti-p-MEK (cat. no. 9121S; Cell Signaling Technology, Inc.), anti-ERK (cat. no. 9102S; Cell Signaling Technology, Inc.), anti-p-ERK (cat. no. sc-7383; Santa Cruz Biotechnology, Inc.), anti-cyclin D1 (cat. no. 29785; Cell Signaling Technology, Inc.), anti-proliferating cell nuclear antigen (PCNA; cat. no. sc-56; Santa Cruz Biotechnology, Inc.), anti- $\beta$-actin (cat. no. ab8227-50; Abcam), anti-caspase-3 (cat. no. ab13847; Abcam) and anti-cleaved caspase-3 (cat. no. ab49822; Abcam). Secondary antibodies were used in these experiments as follows: Goat anti-mouse
IgG (H+L)-HRP (cat. no. SA001-500) and goat anti-rabbit IgG (H+L)-HRP (cat. no. SA002-500) from GenDEPOT, LLC. The amount of phosphorylation was calculated by dividing the amount by the total expression amount. This was clarified using magnification of phosphorylation/expression ratio.

Immunocytochemistry. VSMCs were seeded into four-well plastic cell culture dishes $\left(1 \times 10^{5}\right.$ cells/well $)$ and were treated with $\mathrm{CpO}$ for $24 \mathrm{~h}$ in a $37^{\circ} \mathrm{C}$ incubator. Subsequently, each well was washed with PBS. Cells were then fixed with 4\% paraformaldehyde diluted in PBS for $10 \mathrm{~min}$ at room temperature, after which they were washed twice with PBS and permeabilized for $10 \mathrm{~min}$ at room temperature with $0.2 \%$ Triton X-100 diluted in PBS. After washing with PBS, the cells were blocked in blocking solution (2\% BSA and $10 \%$ horse serum (Vector Laboratories, Inc.; Maravai LifeSciences) in PBS) for $30 \mathrm{~min}$ at room temperature and stained for Ki-67 (Dako; cat. no. M7240; 1:200 dilution) for $1 \mathrm{~h}$ at $37^{\circ} \mathrm{C}$. The cells were incubated with a FITC-conjugated anti-mouse (cat. no. 115-095-003; 1:500 dilution; Jackson ImmunoResearch Laboratories, Inc.) secondary antibody at room temperature for $1 \mathrm{~h}$ and then stained with a DAPI solution $(0.1 \mu \mathrm{l} / \mathrm{ml}$; Thermo Fisher Scientific, Inc.) for $5 \mathrm{~min}$. Immunofluorescence was detected via confocal microscopy (LSM700; Zeiss GmbH) and analyzed using ZEN 2.5 Blue Edition software (Zeiss $\mathrm{GmbH}) 1.0$ for analysis.

Ex vivo aortic ring assay. Ex vivo sprouting of VSMCs was measured via an aortic ring assay using Matrigel (BD Biosciences). The thoracic aortas from the aforementioned 8-week-old Sprague-Dawley rats were removed and transferred into serum-free DMEM. The endothelial lining was removed using a 2-Fr Fogarty balloon catheter (Baxter Healthcare) to minimize the possibility of EC sprouting during the ring assay. The aorta was washed by gradually passing PBS through the aorta three times. After removing perivascular adipose tissue, the aorta was cut into 1-mm-thick segments of aortic ring and placed in Matrigel. The aortic rings were washed with serum-free DMEM twice and starved in DMEM supplemented with $0.5 \% \mathrm{FBS}$ for $24 \mathrm{~h}$ at $37^{\circ} \mathrm{C}$. For the lime $\mathrm{CpO}$ group, the medium was changed to DMEM supplemented with 5\% FBS containing $1 \times 10^{-5}$ diluted lime $\mathrm{CpO}$. The cells were cultured at $37^{\circ} \mathrm{C}$ and the media were changed every 3 days and the aortic rings were monitored daily for up to 7 days for sprouting VSMCs. On the 7th day the results were analyzed.

Statistical analysis. Data are presented as the mean \pm SEM of at least three independent experiments. For statistical analysis, one-way analysis of variance with Bonferroni's correction was performed for comparisons among more than two groups. All analyses were performed using Prism software (version 5.0; GraphPad Software, Inc.). $\mathrm{P}<0.05$ was considered to indicate a statistically significant difference.

\section{Results}

Suppression of VSMC proliferation by lime CpO treatment. To evaluate the effect of lime $\mathrm{CpO}$ on VSMC proliferation, cells were treated with lime $\mathrm{CpO}$ for $24 \mathrm{~h}$. In the group treated with FBS only, the cell proliferation rate was 

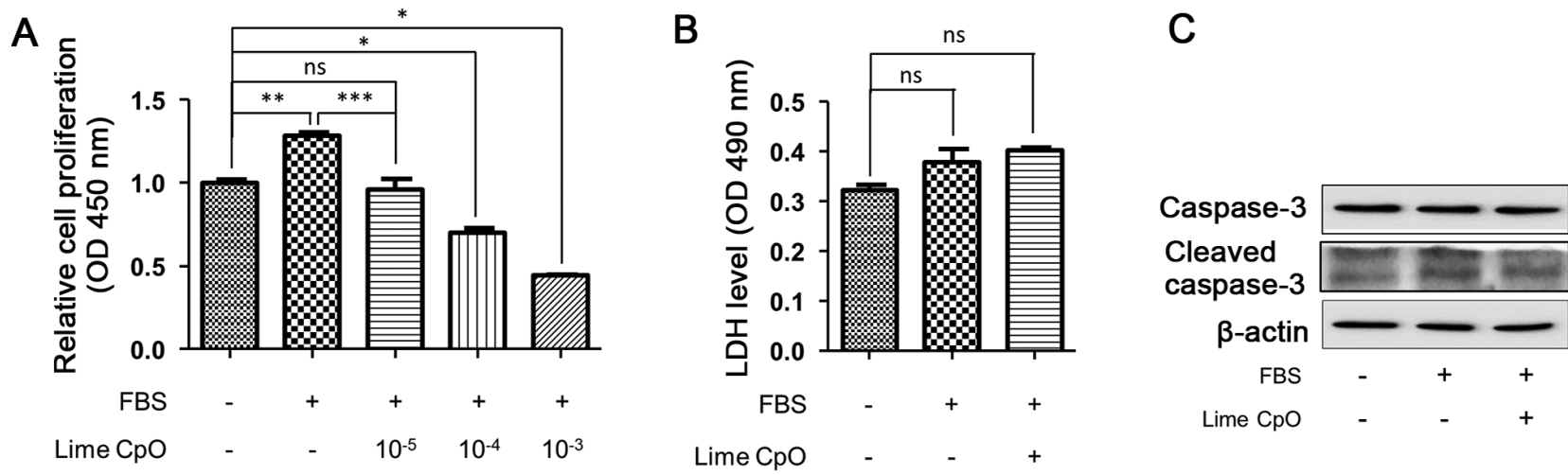

Figure 1. Effects on VSMC proliferation treated with lime CpO. To examine the effect of lime $\mathrm{CpO}$ on VSMC proliferation, concentration of $10^{-3}$ to $10^{-5}$ of lime $\mathrm{CpO}$ was added to 5\% FBS-containing DMEM and VSMCs, and cells were cultured for $24 \mathrm{~h}$. (A) Cell proliferation was determined using a CCK-8 assay. (B) To measure cytotoxicity the LDH assay was performed. (C) Following lime $\mathrm{CpO}$ treatment, the protein expression levels of caspase-3 and cleaved caspase-3 were analyzed via western blotting. Data are presented as the mean $\pm \mathrm{SD}$. ${ }^{*} \mathrm{P}<0.05,{ }^{* *} \mathrm{P}<0.01$ and ${ }^{* * *} \mathrm{P}<0.001$. CCK-8, Cell Counting Kit-8; CpO, cold-pressed oil; LDH, lactate dehydrogenase; ns, not significant; OD, optical density; VSMC, vascular smooth muscle cell.

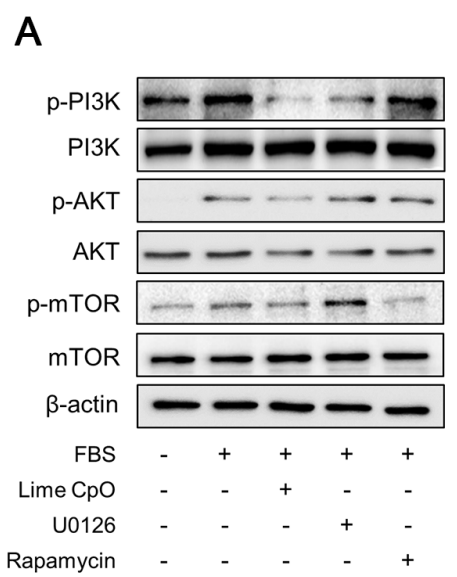

$E$

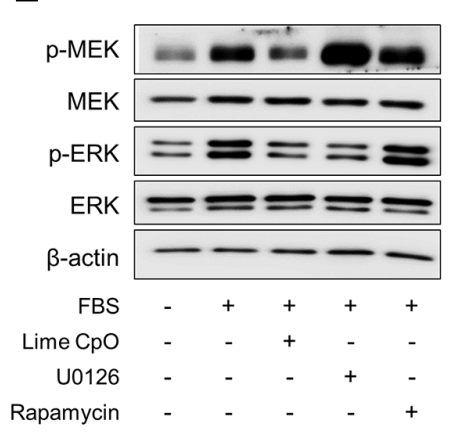

B

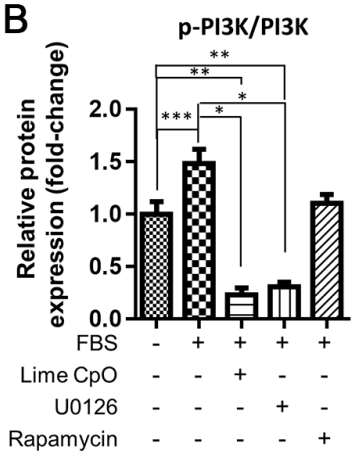

F

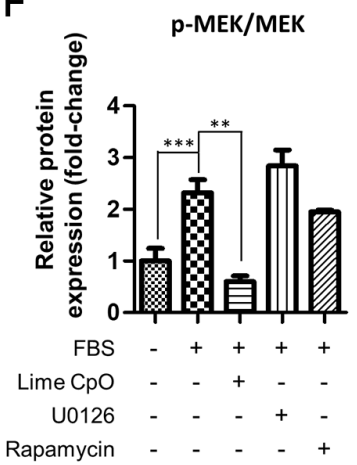

C

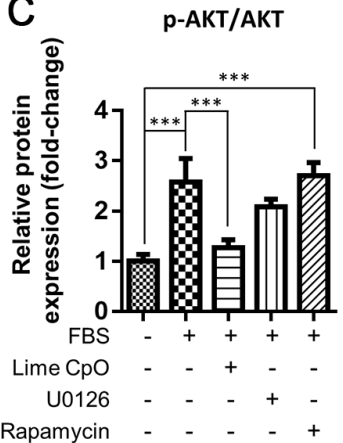

D $\quad$-mTOR/mTOR

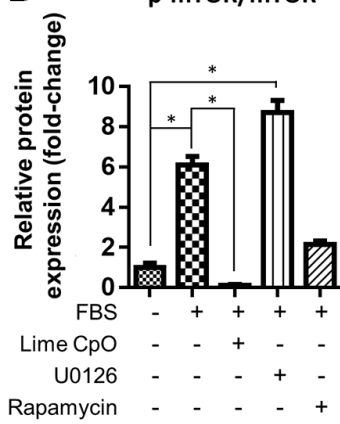

G

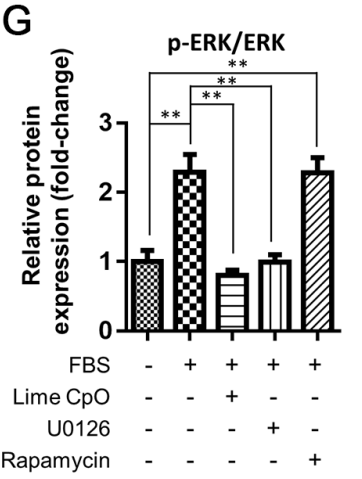

$\mathrm{H}$

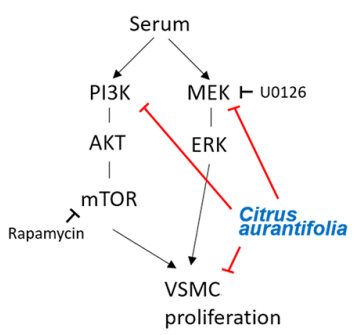

Figure 2. Changes of PI3K and MAPK signaling pathways in VSMC treated with lime CpO. To investigate the effect of lime CpO on cell proliferation, related signaling cascades were analyzed using western blotting. Starved cells were pretreated with $10^{-5}$ diluted lime CpO for $1 \mathrm{~h}$ prior to FBS treatment. (A) PI3K/AKT/mTOR signaling cascade was investigated following 30 min of FBS treatment. (B-D) Protein expression levels and phosphorylation of PI3K, AKT and mTOR were semi-quantified using ImageJ. (E) MEK/ERK signaling cascade was investigated following 30 min of FBS treatment. (F and G) Protein expression levels and phosphorylation of MEK and ERK were semi-quantified using ImageJ. (H) Diagram showing the role of lime CpO in the signaling cascades related to VSMC proliferation. ${ }^{*} \mathrm{P}<0.001,{ }^{* * *} \mathrm{P}<0.01$ and ${ }^{* * * *} \mathrm{P}<0.05$. CpO, cold-pressed oil; $\mathrm{p}$, phosphorylated; VSMC, vascular smooth muscle cell.

significantly increased by $\sim 30 \%$ compared with that of the FBS-negative and lime $\mathrm{CpO}$-negative control groups. Concentration of 10-5 lime $\mathrm{CpO}$ was statistically similar to the control, however concentration of $10^{-4}$ and $10^{-3}$ lime $\mathrm{CpO}$ was significantly lower (Fig. 1A). Based on these results, lime CpO significantly inhibited FBS-stimulated VSMC proliferation at low concentrations $\left(10^{-5}\right)$. The effect of lime
$\mathrm{CpO}$ on cell death was assessed via LDH analysis and it was demonstrated to have no statistically significant effect on cell death compared with the FBS-treated only group (Fig. 1B). Furthermore, caspase- 3 and cleaved caspase-3 protein levels were also not affected by lime $\mathrm{CpO}$ treatment compared with the FBS-treated or FBS-negative and lime CpO-negative control groups (Fig. 1C). Therefore, the results suggested that 
A

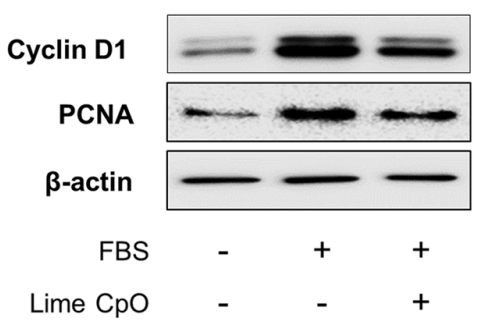

$\mathrm{D}$

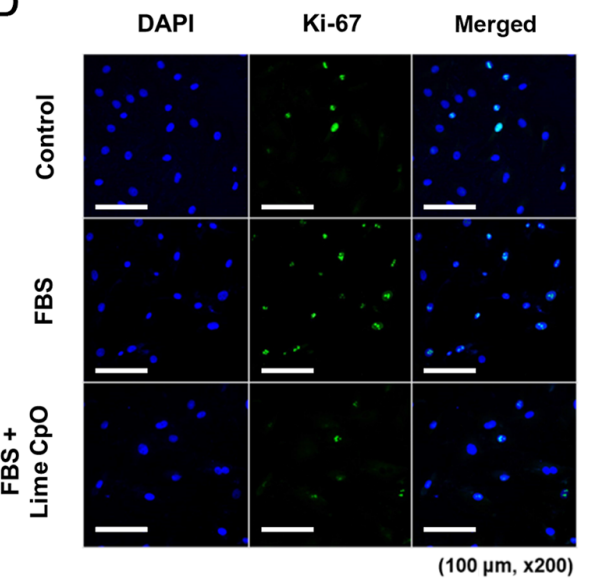

B

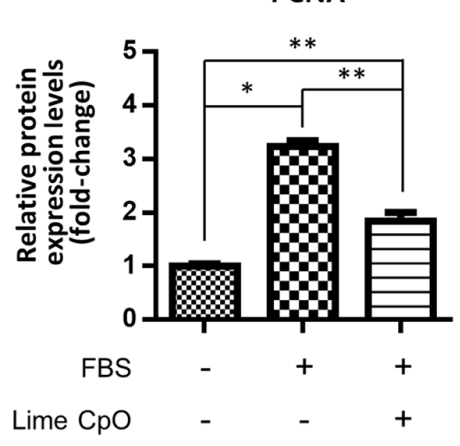

$E$

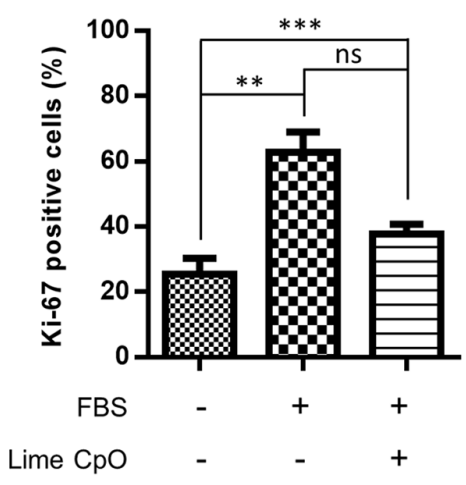

C

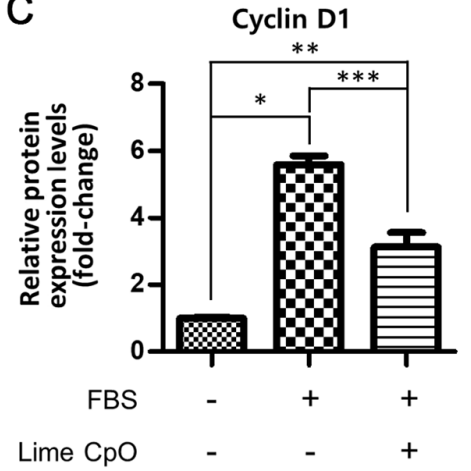

Figure 3. Regulation of the cell cycle in VSMCs by treating lime CpO. (A) Effects of lime CpO on cell cycle-related proteins (cyclin D1 and PCNA) were analyzed using western blotting. Protein expression levels of (B) PCNA and (C) cyclin D1 were semi-quantified using ImageJ. (D) Following lime CpO treatment, Ki-67 was immunostained. Green, Ki-67; blue, DAPI. Scale bar, $100 \mu \mathrm{m}$. (E) Percentages of Ki-67-positive VSMCs were quantified by counting the number of Ki-67 (green) labeled cells divided by DAPI (blue) labeled cells (five individual fields $/$ group). ${ }^{*} \mathrm{P}<0.001,{ }^{* *} \mathrm{P}<0.01$ and ${ }^{* * *} \mathrm{P}<0.05$. CpO, cold-pressed oil; Ctl, control; ns, not significant; PCNA, proliferating cell nuclear antigen; VSMC, vascular smooth muscle cell.

lime CpO may inhibit FBS-induced proliferation of VSMCs but does not cause cell death.

Changes in AKT and ERK signaling cascades in VSMC proliferation. The mechanism by which lime $\mathrm{CpO}$ regulated proliferation was investigated further. Since phosphorylation of the PI3K/AKT/mTOR signaling cascade is known to regulate VSMC proliferation (27), the phosphorylation of these signaling cascades was analyzed. Phosphorylation of the PI3K/AKT/mTOR (Fig. 2A-D) and MEK/ERK signaling pathways (Fig. 2E-G) was significantly increased by 1.5-6.2-fold in FBS-treated cells compared with the FBS-negative and lime $\mathrm{CpO}$-negative control group. However, the signal intensity of each phosphorylated protein band was significantly reduced in the lime CpO-treated group compared with the FBS-treated cells or the U0126 or Rapamycin-treated cells. These results demonstrated that lime $\mathrm{CpO}$ inhibited phosphorylation in a manner similar to that of the MEK and mTOR inhibitors in VSMCs (Fig. 2H).

Regulation of cell cycle regulators in VSMCs. It was subsequently demonstrated that the cell cycle-regulating factors cyclin D1 and PCNA were essential for regulating proliferation in lime $\mathrm{CpO}$-treated cells. The protein expression levels of cyclin D1 and PCNA were significantly increased in FBS-treated cells compared with FBS-negative and lime CpO-negative control cells; however, the lime CpO-treated cells displayed significantly reduced protein expression levels compared with the FBS-treated cells (Fig. 3A-C). Ki-67 was observed in the nucleus during cell division, indicating cell proliferation (Fig. 3D-E). The number of Ki-67-positive cells was significantly increased by $\sim 35 \%$ in the FBS-treated group compared with the FBS-negative and lime $\mathrm{CpO}$-negative control group. However, the number of $\mathrm{Ki}-67$-positive cells was significantly reduced in the lime $\mathrm{CpO}$-treated group compared with the FBS-treated group (Fig. 3D and E). This result suggested that lime $\mathrm{CpO}$ had the potential to suppress the cell cycle of VSMCs and regulate VSMC proliferation.

Inhibition of VSMC proliferation in endothelium-denuded aortic rings. The effect of lime $\mathrm{CpO}$ on the proliferation and migration of VSMCs in tissues was investigated and an ex vivo aortic ring analysis was performed (Fig. 4A). EC-denuded vascular tissue was cultured in DMEM containing FBS to observe the proliferation and migration of VSMCs. Intravascular VSMCs spread to the outside of the aortic rings and significantly proliferated in response to FBS compared with the cells in the FBS-negative and lime CpO-negative control group. However, the degree of spread of the lime $\mathrm{CpO}$ and FBS-treated VSMCs was significantly decreased 
A
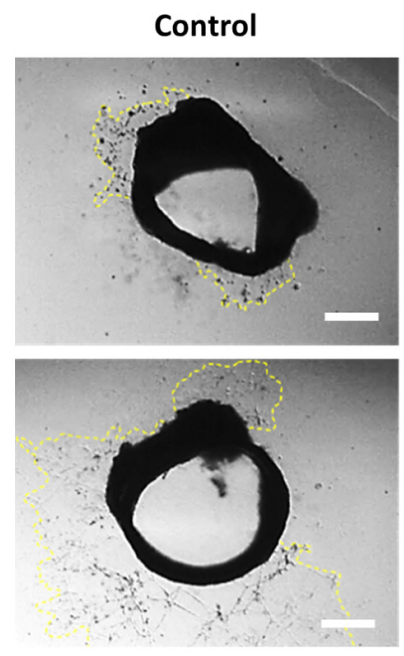

FBS
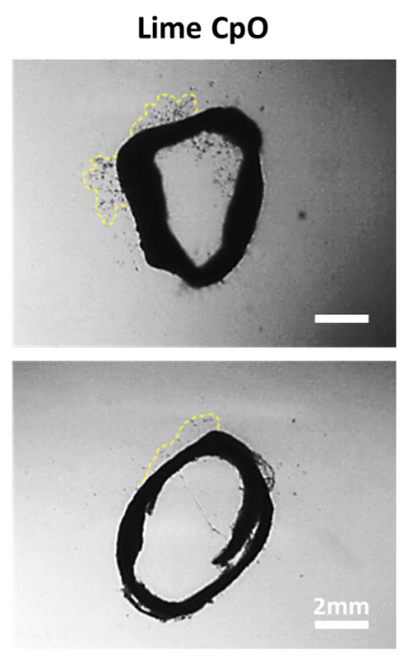

FBS + Lime CpO
B

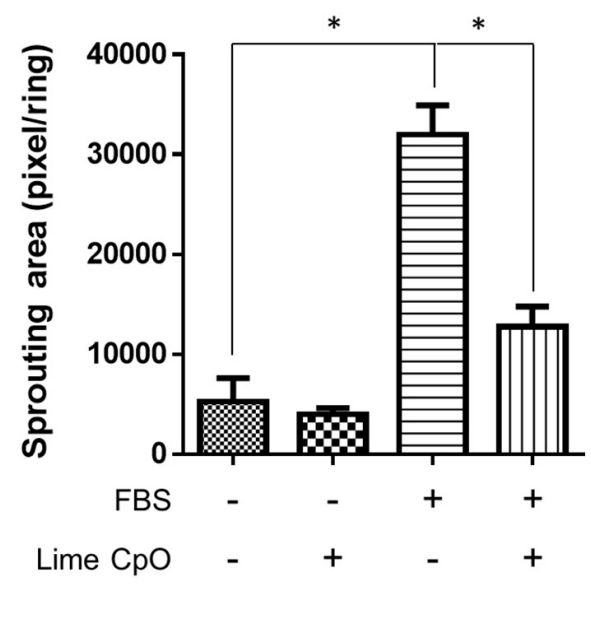

Figure 4. Inhibition of VSMC-sprouting from endothelium-denuded aortic rings treated with lime CpO. To investigate the effects of lime CpO on VSMC increase in blood vessels, a 1-mm-thick aortic ring was built into the Matrigel and cultivated for 7 days with DMEM containing $5 \%$ FBS and/or lime CpO. (A) Yellow-dotted lines indicate the sprouting of VSMCs from the aortic rings. Scale bar, $2 \mathrm{~mm}$. (B) VSMC sprouting, as indicated by the area inside the dotted line, was quantified using ImageJ. * $\mathrm{P}<0.001$. CpO, cold-pressed oil; Ctl, control; VSMC, vascular smooth muscle cell.

compared with the FBS-treated group, to a similar level to that of the control cells (treated with nether CpO or FBS) (Fig. 4B). These results suggested that lime $\mathrm{CpO}$ inhibited abnormal VSMC proliferation in injured vascular tissues and possibly contributed to tissue homeostasis.

Analysis of lime CpO components. In the present study, GC-MS analysis was performed to evaluate the characteristics and components of lime $\mathrm{CpO}$ (Table I). Table I displays the results of the component analysis of lime CpO by GC-MS. In total, 36 types of volatile compounds were detected as main materials, including 23 monoterpenes, 9 sesquiterpenes and 4 other components. Monoterpenes (M) and sesquiterpenes (S) accounted for 94.6 and $4.6 \%$ of EOs, respectively, in summed area \% of GC-MS spectrometry (Table I). D-limonene (41.40\%), $\gamma$-terpinene $(13.19 \%)$, terpinolene $(10.41 \%)$ and $\alpha$-terpineol (8.61\%) were the major monoterpenes among the detected volatile components, overall accounting for $73.61 \%$ of the total volatile components (Table I).

\section{Discussion}

The present study investigated the effect of lime $\mathrm{CpO}$, a natural substance, on VSMC proliferation. To examine whether lime $\mathrm{CpO}$ was involved in VSMC regulation, cellular signaling pathways were analyzed using western blotting. Lime $\mathrm{CpO}$ was demonstrated to modulate cell cycle regulators in VSMCs. Furthermore, in ex vivo conditions, lime $\mathrm{CpO}$ negatively regulated VSMC proliferation. Among 36 types of volatile compounds identified in lime $\mathrm{CpO}$, four molecules (D-limonene, $\gamma$-terpinene, terpinolene and $\alpha$-terpineol) were specifically detected as the main components.

In the past decade, natural products have been demonstrated to be mostly non-toxic and have been used successfully as therapeutics for numerous diseases (10,28-30). Among these natural products, EOs are promising pharmaceutical agents as they are clinically applicable and can be properly managed and industrialized for human diseases (31). Depending on the EO extraction method, such as steam distillation, expression (for example cold compression) and solvent extraction, the properties of the active compounds may show different distribution ratio in total ingredients, but the main active substances remain unchanged (32). According to a review by Narang and Jiraungkoorskul (17), lime and its related byproducts have been suggested to have potential therapeutic effects in colon cancer, pancreatic cancer, breast cancer, skin cancer and lymphoma. Lime and its related byproducts have also been demonstrated to inhibit the cell cycle and cell proliferation (17). Patil et al (18) reported that lime inhibited cancer cell proliferation by modulating Bax, Bcl-2, caspase-3 and p53 in pancreatic cancer cells. Furthermore, lime has been reported to improve obesity, the atherogenic index and fatty liver disease by inducing antioxidant capacity and hypolipidemic effects (33). Despite the various previous studies on lime $\mathrm{CpO}$, to the best of our knowledge, there are currently no reports on the inhibition of VSMC proliferation, a major cause of occlusive vascular disease.

The present study demonstrated that lime $\mathrm{CpO}$ treatment at $10^{-5}$ concentrations inhibited FBS-induced VSMC proliferation. Furthermore, lime $\mathrm{CpO}$ reduced FBS-induced phosphorylation of the MAPK/ERK and PI3K/AKT/mTOR signaling pathways. Lime $\mathrm{CpO}$ inhibited the MAPK/ERK and $\mathrm{PI} 3 \mathrm{~K} / \mathrm{AKT} / \mathrm{mTOR}$ signaling pathways at comparable or higher degree. However, there was no change in the expression or activity of caspase-3 under the experimental conditions of the present study. A possible reason for why these results differed from previous reports is that the lime $\mathrm{CpO}$ dose is modifiable for different cytotoxic effects under various cell types. In the present study, preliminary experiments were conducted to determine concentrations that were not cytotoxic (Fig. 1A). Compared with conventional chemical drugs, lime $\mathrm{CpO}$ is a natural compound with little 
Table I. Chemical Composition of Lime CpO by MS and KI identification in GC-MS spectrometry.

\begin{tabular}{|c|c|c|c|c|}
\hline RT & Constituent & Area, \% & $\mathrm{KI}^{\mathrm{a}}$ & Classification \\
\hline 24.55 & $\alpha$-Pinene & 0.90 & 927 & $(\mathrm{M})$ \\
\hline 27.08 & Camphene & 0.26 & 943 & $(\mathrm{M})$ \\
\hline 30.36 & Linalool-3,7-oxide & 0.10 & 963 & $(\mathrm{M})$ \\
\hline 31.89 & $\beta$-Pinene & 1.48 & 972 & $(\mathrm{M})$ \\
\hline 34.15 & $\beta$-Myrcene & 0.36 & 986 & $(\mathrm{M})$ \\
\hline 39.22 & 1,4-Cineole & 1.39 & 1026 & $(\mathrm{M})$ \\
\hline 39.52 & $\alpha$-Terpinene & 1.05 & 1029 & $(\mathrm{M})$ \\
\hline 40.61 & @-Cymene & 4.23 & 1039 & $(\mathrm{M})$ \\
\hline 41.27 & D-Limonene & 41.40 & 1045 & $(\mathrm{M})$ \\
\hline 41.50 & Eucalyptol & 1.11 & 1048 & $(\mathrm{M})$ \\
\hline 42.77 & Ocimene quintoxide & 0.12 & 1059 & $(\mathrm{O})$ \\
\hline 42.98 & $(Z)-\beta$-Ocimene & 0.32 & 1061 & $(\mathrm{M})$ \\
\hline 44.08 & $\gamma$-Terpinene & 13.19 & 1072 & $(\mathrm{M})$ \\
\hline 46.19 & Terpinolene & 10.41 & 1092 & $(\mathrm{M})$ \\
\hline 46.57 & @-Cymenene & 0.33 & 1095 & $(\mathrm{M})$ \\
\hline 47.14 & Linalool & 0.13 & 1101 & $(\mathrm{M})$ \\
\hline 48.49 & Fenchyl alcohol & 0.48 & 1121 & $(\mathrm{M})$ \\
\hline 49.53 & 1-Terpineol & 0.58 & 1136 & $(\mathrm{M})$ \\
\hline 50.48 & $\beta$-Terpineol & 0.72 & 1150 & $(\mathrm{M})$ \\
\hline 51.79 & Decanal & 0.25 & 1169 & $(\mathrm{O})$ \\
\hline 52.22 & endo-Borneol & 0.18 & 1175 & $(\mathrm{M})$ \\
\hline 52.77 & Terpinen-4-ol & 0.44 & 1183 & $(\mathrm{M})$ \\
\hline 53.24 & Q-Cymen-8-ol & 0.20 & 1190 & $(\mathrm{M})$ \\
\hline 53.92 & $\alpha$-Terpineol & 8.61 & 1200 & $(\mathrm{M})$ \\
\hline 54.26 & $\gamma$-Terpineol & 1.63 & 1204 & $(\mathrm{M})$ \\
\hline 68.01 & trans-Caryophyllene & 0.47 & 1434 & $(\mathrm{~S})$ \\
\hline 68.33 & $\alpha$-Bergamotene & 0.78 & 1442 & $(\mathrm{~S})$ \\
\hline 68.89 & $\beta$-Farnesene & 0.10 & 1457 & $(\mathrm{~S})$ \\
\hline 69.39 & $\alpha$-Humulene & 0.13 & 1471 & $(\mathrm{~S})$ \\
\hline 69.95 & $\alpha$-Selinene & 0.14 & 1486 & $(\mathrm{~S})$ \\
\hline 70.42 & $\beta$-Cadinene & 0.17 & 1498 & $(\mathrm{~S})$ \\
\hline 70.69 & $\alpha$-Farnesene & 0.75 & 1507 & $(\mathrm{~S})$ \\
\hline 70.95 & $\beta$-Bisabolene & 1.52 & 1516 & $(\mathrm{~S})$ \\
\hline 71.94 & $\beta$-Maaliene & 0.26 & 1548 & $(\mathrm{~S})$ \\
\hline 89.83 & Butyl palmitate & 0.24 & 2188 & $(\mathrm{O})$ \\
\hline 91.85 & Butyl stearate & 0.20 & 2389 & $(\mathrm{O})$ \\
\hline
\end{tabular}

${ }^{a} \mathrm{KI}$ on a DB-5 column in reference to n-alkanes. MS, National Institute of Standards and Technology, Environmental Protection Agency and National Institutes of Health Mass Spectral Library; KI, Kovats retention index; RT, Retention time; M, monoterpenes, S, sesquiterpenes; O, others.

to no toxicity and controllable doses that can be used in the body (34). The use of natural products as therapeutics is advantageous as they are traditionally used by human and therefore less likely to cause an adverse reaction when developed as medicines (9). However, in future work, lime $\mathrm{CpO}$ toxicity will be tested in other vascular constituent cells besides VSMCs, such as vascular ECs and vascular fibroblasts. Furthermore, whether the same effect is shown in other batches of lime $\mathrm{CpO}$ and identification of the active compounds via selection experiments with various combina- tions of constituents from lime $\mathrm{CpO}$ should be investigated in future studies.

A previous report suggested that neroli (Citrus aurantium L.) EO is an endothelium and smooth muscle-dependent vasodilator, which alleviates cardiovascular disease (35). It has been reported that neroli EO modulated intracellular $\mathrm{Ca}^{2+}$ concentrations via the inhibition of cation channel-mediated extracellular $\mathrm{Ca}^{2+}$ influx and store-operated $\mathrm{Ca}^{2+}$ release mediated by the ryanodine receptor signaling pathway (35). Among the proposed constituent compounds of neroli EO, 
D-limonene and $\alpha$-terpineol are included in the data from the present study, suggesting that lime $\mathrm{CpO}$ may also act as a smooth muscle-dependent vasodilator (35). Furthermore, neroli EO have also reported to possess $100 \%$ singlet oxygen scavenging activity as a strong antioxidant $(12,36,37)$. Therefore, future work may examine the endothelium and/or smooth muscle-mediated vasodilator effect of lime $\mathrm{CpO}$ in a cardiovascular disease model. In the present study, lime $\mathrm{CpO}$ inhibited excess VSMC proliferation, which causes occlusive vascular disease, via the regulation of MAPK and PI3K signaling pathways. These results suggest that lime $\mathrm{CpO}$ may be developed as a potential therapeutic or health supplement for the treatment of cardiovascular disease. Future studies may explore the different effects of lime $\mathrm{CpO}$ compared with lime EO and validate its pharmacological effects on classified compounds including D-limonene, $\gamma$-terpinene, terpinolene and $\alpha$-terpineol to investigate the proposed molecules of in vivo cardiovascular disease.

\section{Acknowledgements}

Not applicable.

\section{Funding}

The present study was supported by the following grants from the Korea Forest Service (Seoul, Korea): Forest Science Technology Research and Development Project (grant no. 2017026B10-1719-BA01) and the National Institute of Forest Science, Forest Science Technology Research and Development Project (grant no. FP0900-2016-01).

\section{Availability of data and materials}

The datasets used and/or analyzed during the current study are available from the corresponding author on reasonable request.

\section{Authors' contributions}

BWS, CYL and IKK were involved in the conceptualization, writing, editing and data analysis. JHP, BK, SLe, SLi, SWK, JWC, MK, JHK, SSL, MJP, HM and $\mathrm{KCH}$ performed and analyzed the experiments, and edited the manuscript. BWS and IKK confirm the authenticity of all the raw data. All authors have read and approved the final manuscript.

\section{Ethics approval and consent to participate}

The present study was performed according to a protocol approved by the Institutional Animal Care and Use Committee of Catholic Kwandong University (approval no. CKU 01-2019-008; Incheon, South Korea).

\section{Patient consent for publication}

Not applicable.

\section{Competing interests}

The authors declare that they have no competing interests.

\section{References}

1. Rensen SSM, Doevendans PAFM and van Eys GJJM: Regulation and characteristics of vascular smooth muscle cell phenotypic diversity. Neth Heart J 15: 100-108, 2007.

2. Hao H, Gabbiani G and Bochaton-Piallat ML: Arterial smooth muscle cell heterogeneity: Implications for atherosclerosis and restenosis development. Arterioscler Thromb Vasc Biol 23: 1510-1520, 2003.

3. Morgan JP, Perreault CL and Morgan KG: The cellular basis of contraction and relaxation in cardiac and vascular smooth muscle. Am Heart J 121: 961-968, 1991.

4. Sprague AH and Khalil RA: Inflammatory cytokines in vascular dysfunction and vascular disease. Biochem Pharmacol 78: 539-552, 2009.

5. Gomez D and Owens GK: Smooth muscle cell phenotypic switching in atherosclerosis. Cardiovasc Res 95: 156-164, 2012.

6. Anwar MA, Shalhoub J, Lim CS, Gohel MS and Davies AH: The effect of pressure-induced mechanical stretch on vascular wall differential gene expression. J Vasc Res 49: 463-478, 2012.

7. Owens GK, Kumar MS and Wamhoff BR: Molecular regulation of vascular smooth muscle cell differentiation in development and disease. Physiol Rev 84: 767-801, 2004.

8. Clowes AW and Reidy MA: Prevention of stenosis after vascular reconstruction: Pharmacologic control of intimal hyperplasia - a review. J Vasc Surg 13: 885-891, 1991.

9. Garg S and Serruys PW: Coronary stents: Current status. J Am Coll Cardiol 56 (Suppl 10): S1-S42, 2010.

10. de Andrade TU, Brasil GA, Endringer DC, da Nóbrega FR and de Sousa DP: Cardiovascular activity of the chemical constituents of essential oils. Molecules 22: E1539, 2017.

11. Amorati R, Foti MC and Valgimigli L: Antioxidant activity of essential oils. J Agric Food Chem 61: 10835-10847, 2013.

12. Dosoky NS and Setzer WN: Biological activities and safety of Citrus spp. essential oils. Int J Mol Sci 19: 1966, 2018.

13. Reis D and Jones T: Aromatherapy: Using Essential Oils as a Supportive Therapy. Clin J Oncol Nurs 21: 16-19, 2017.

14. Spadaro F, Costa R, Circosta C and Occhiuto F: Volatile composition and biological activity of key lime Citrus aurantifolia essential oil. Nat Prod Commun 7: 1523-1526, 2012.

15. Amorim JL, Simas DLR, Pinheiro MMG, Moreno DSA, Alviano CS, da Silva AJR and Fernandes PD: Anti-inflammatory properties and chemical characterization of the essential oils of four Citrus species. PLoS One 11: e0153643, 2016.

16. Kummer R, Fachini-Queiroz FC, Estevão-Silva CF, Grespan R, Silva EL, Bersani-Amado CA and Cuman RKN: Evaluation of anti-inflammatory activity of Citrus latifolia Tanaka essential oil and limonene in experimental mouse models. Evid Based Complement Alternat Med 2013: 859083, 2013.

17. Narang $\mathrm{N}$ and Jiraungkoorskul W: Anticancer Activity of Key Lime, Citrus aurantifolia. Pharmacogn Rev 10: 118-122, 2016.

18. Patil JR, Chidambara Murthy KN, Jayaprakasha GK, Chetti MB and Patil BS: Bioactive compounds from Mexican lime (Citrus aurantifolia) juice induce apoptosis in human pancreatic cells. J Agric Food Chem 57: 10933-10942, 2009.

19. Tosukhowong P, Yachantha C, Sasivongsbhakdi T, Ratchanon S, Chaisawasdi S, Boonla C and Tungsanga K: Citraturic, alkalinizing and antioxidative effects of limeade-based regimen in nephrolithiasis patients. Urol Res 36: 149-155, 2008.

20. Boshtam M, Moshtaghian J, Naderi G, Asgary S and Nayeri $\mathrm{H}$ : Antioxidant effects of Citrus aurantifolia (Christm) juice and peel extract on LDL oxidation. J Res Med Sci 16: 951-955, 2011.

21. Kato Y, Domoto T, Hiramitsu M, Katagiri T, Sato K, Miyake Y, Aoi S, Ishihara $\mathrm{K}$, Ikeda $\mathrm{H}$, Umei N, et al: Effect on blood pressure of daily lemon ingestion and walking. J Nutr Metab 2014: 912684 , 2014.

22. Muslin AJ: MAPK signalling in cardiovascular health and disease: Molecular mechanisms and therapeutic targets. Clin Sci (Lond) 115: 203-218, 2008.

23. Muto A, Fitzgerald TN, Pimiento JM, Maloney SP, Teso D, Paszkowiak JJ, Westvik TS, Kudo FA, Nishibe T and Dardik A: Smooth muscle cell signal transduction: implications of vascular biology for vascular surgeons. J Vasc Surg 45 (Suppl A): A15-A24, 2007.

24. National Research Council (US) Committee for the Update of the Guide for the Care and Use of Laboratory Animals: Guide for the Care and Use of Laboratory Animals, 8th edition. National Academies Press (US), Washington, DC, 2011. 
25. Chang W, Lim S, Song H, Song BW, Kim HJ, Cha MJ, Sung JM, Kim TW and Hwang KC: Cordycepin inhibits vascular smooth muscle cell proliferation. Eur J Pharmacol 597: 64-69, 2008.

26. Lim S, Lee SY, Seo HH, Ham O, Lee C, Park JH, Lee J, Seung M, Yun I, Han SM, et al: Regulation of mitochondrial morphology by positive feedback interaction between PKC $\delta$ and Drp1 in vascular smooth muscle cell. J Cell Biochem 116: 648-660, 2015.

27. Mathew OP, Ranganna K, Mathew J, Zhu M, Yousefipour Z, Selvam C and Milton SG: Cellular effects of butylate on vascular smooth muscle cells are mediated through disparate actions on dual targets, histone deacetylase (HDAC) activity and PI3K/Akt signaling network. Int J Mol Sci 20: 2902, 2019.

28. Suen J, Thomas J, Kranz A, Vun S and Miller M: Effect of flavonoids on oxidative stress and inflammation in adults at risk of cardiovascular disease: a systematic review. Healthcare (Basel) 4: 69, 2016.

29. Li D, Wu H, Dou H, Guo L and Huang W: Microcapsule of sweet orange essential oil changes gut microbiota in diet-induced obese rats. Biochem Biophys Res Commun 505: 991-995, 2018.

30. Jiang D, Li D and Wu W: Inhibitory effects and mechanisms of luteolin on proliferation and migration of vascular smooth muscle cells. Nutrients 5: 1648-1659, 2013.

31. Lv X, Zhao S, Ning Z, Zeng H, Shu Y, Tao O, Xiao C, Lu C and Liu Y: Citrus fruits as a treasure trove of active natural metabolites that potentially provide benefits for human health. Chem Cent J 9: 68, 2015
32. Aziz ZAA, Ahmad A, Setapar SHM, Karakucuk A, Azim MM, Lokhat D, Rafatullah M, Ganash M, Kamal MA and Ashraf GM: Essential oils: extraction techniques, pharmaceutical and therapeutic potential - a review. Curr Drug Metab 19: 1100-1110, 2018.

33. Lin LY, Chuang $\mathrm{CH}$, Chen $\mathrm{HC}$ and Yang KM: Lime (Citrus aurantifolia (Christm.) swingle) essential oils: volatile compounds, antioxidant capacity, and hypolipidemic effect. Foods 8: E398, 2019.

34. Adokoh CK, Asante DB, Acheampong DO, Kotsuchibashi Y, Armah FA, Sirikyi IH, Kimura K, Gmakame E and Abdul-Rauf S: Chemical profile and in vivo toxicity evaluation of unripe Citrus aurantifolia essential oil. Toxicol Rep 6: 692-702, 2019.

35. Kang P, Ryu K-H,Lee J-M, Kim H-K and Seol GH: Endotheliumand smooth muscle-dependent vasodilator effects of Citrus aurantium L. var. amara: Focus on $\mathrm{Ca}(2+)$ modulation. Biomed Pharmacother 82: 467-471, 2016.

36. Ammar AH, Bouajila J, Lebrihi A, Mathieu F, Romdhane M and Zagrouba F: Chemical composition and in vitro antimicrobial and antioxidant activities of Citrus aurantium L. flowers essential oil (Neroli oil). Pak J Biol Sci 15: 1034-1040, 2012.

37. Ao Y, Satoh K, Shibano K, Kawahito Y and Shioda S: Singlet oxygen scavenging activity and cytotoxicity of essential oils from rutaceae. J Clin Biochem Nutr 43: 6-12, 2008.

cc (i) $($ This work is licensed under a Creative Commons C. Attribution-NonCommercial-NoDerivatives 4.0 International (CC BY-NC-ND 4.0) License. 